\title{
Management of tracheobronchial injuries
}

\author{
Stefan Welter, Weam Essaleh
}

Department of Thoracic Surgery, Lung Clinic Hemer, Hemer, Germany

Contributions: (I) Conception and design: S Welter; (II) Administrative support: S Welter; (III) Provision of study materials or patients: S Welter; (IV) Collection and assembly of data: All authors; (V) Data analysis and interpretation: All authors; (VI) Manuscript writing: All authors; (VII) Final approval of manuscript: All authors.

Correspondence to: Stefan Welter. Department of Thoracic Surgery, Lungenklinik Hemer, Theo-Funccius-Str.1, 58675 Hemer, Germany.

Email: Stefan.welter@lkhemer.de.

\begin{abstract}
Tracheobronchial injuries (TBI) are a heterogenous group of sometimes life-threatening traumas with different management approaches. Symptoms are mediastinal and subcutaneous emphysema, bloody secretions from the airway or haemoptysis in alert patients, and high air leakage along the cuff or increased ventilatory resistance may be signs for TBI in intubated patients. The necessity of immediate clinical evaluation, CT-scan and bronchoscopic evaluation are essential for prompt diagnosis and classification as well as experienced air way management and treatment, these patients are best managed from interdisciplinary teams including thoracic surgeons. While iatrogenic tracheal membrane laceration from intubation can be treated by lesion bridging with ventilation tube, stent application, open operative repair or endoluminal repair, intraoperative accidental cuts should be repaired by direct suture or with vital tissue coverage in case of local ischemia. The management of blunt or penetrating injury is sequential and needs immediate establishment and maintenance of a secure patent airway to provide adequate oxygenation. The next step is the treatment of life-threatening collateral injuries like major hemorrhage, cranial trauma or major organ damage arranged in the trauma team. The treatment of penetrating injuries to the airway need operative exploration in almost every case with minimal local dissection and debridement followed by direct repair. Muscle flap coverage is useful in case of combined esophageal injury. Damage of the tracheobronchial tree after blunt trauma must be repaired by direct suture or local tissue sparing resection and anastomosis. These lesions can be missed in the initial phase and may become prominent with scar tissue formation, stenosis and atelectasis in the later phases.
\end{abstract}

Keywords: Tracheobronchial injury; tracheal membrane laceration; endoluminal repair; secure airway

Submitted Dec 09, 2019. Accepted for publication Mar 25, 2020.

doi: 10.21037/jtd-2019-as-05

View this article at: http://dx.doi.org/10.21037/jtd-2019-as-05

\section{Introduction}

Injuries of the tracheobronchial system are often life threatening. The anatomy with the larynx and trachea guiding oxygen through a single lumen into bilateral bronchial systems with around 20 generations of dichotomous bronchial divisions into the alveoli, may explain, why injuries to central airways are so dangerous. Disruption or occlusion of the trachea leads to asphyxia within a few minutes. So, the vital measures in case of central airway trauma is to secure the airway immediately.
Because the mechanism of trauma, monitoring of the patient, medical care and severity of damage and subsequent complications completely vary between iatrogenic and non-iatrogenic tracheobronchial injury (TBI) we prefer to describe the two situations separately. Whereas TBIs due to blunt trauma and due to intubation are most frequent in western countries, penetrating injuries dominate in war zones. To our knowledge, there are no randomized or non-randomized prospective studies on TBIs so that all our knowledge results from retrospective case reports or larger case series. This situation might be explained by 
Table 1 Main differences of iatrogenic and traumatic (non-iatrogenic) tracheobronchial injuries (TBI)

\begin{tabular}{lll}
\hline Characteristics & latrogenic TBI & Non-iatrogenic TBI \\
\hline Trauma mechanism & $\begin{array}{l}\text { Intubation; dilatational tracheostomy; } \\
\text { reinsertion of tracheostomy canula; } \\
\text { unintended intraoperative damage }\end{array}$ & $\begin{array}{l}\text { Road accident; crush injury; burying; stab injuries; gun-shot; } \\
\text { hyperextension of the neck; hanging, strangulation }\end{array}$ \\
$\begin{array}{ll}\text { Concomitant injuries } \\
\text { Affected neighboring } \\
\text { organs }\end{array}$ & $\begin{array}{l}\text { Esophagus; mediastinal pleura; } \\
\text { bracheocephalic vessels }\end{array}$ & $\begin{array}{l}\text { Frequent } \\
\text { Osseous structures of the thorax (ribs, sternum, spine); lungs; } \\
\text { Vital endangering }\end{array}$ \\
$\begin{array}{l}\text { Comorbidities; pneumomediastinum; } \\
\text { pneumothorax }\end{array}$ & $\begin{array}{l}\text { Airway disruption/-occlusion; injuries of other vital organs; tension } \\
\text { pneumothorax }\end{array}$ \\
\hline
\end{tabular}

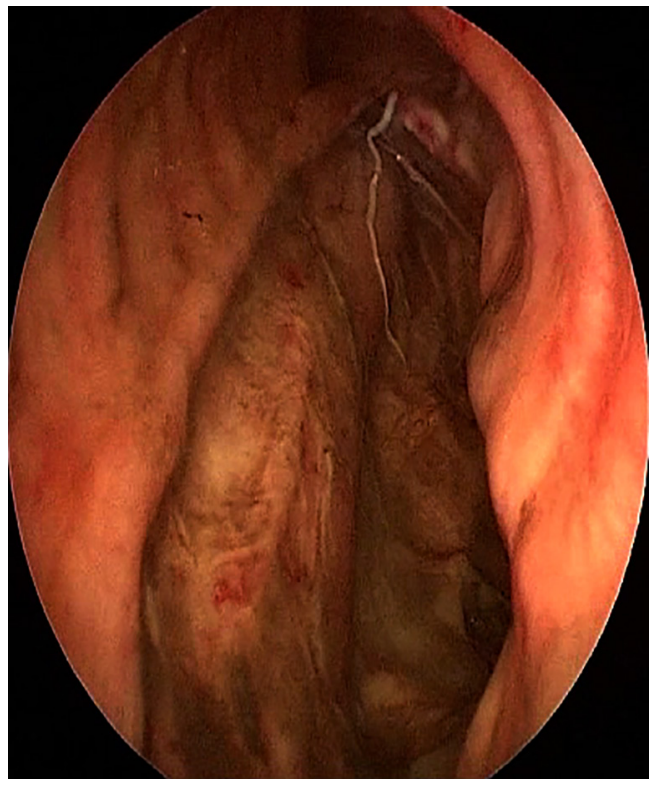

Figure $1 \mathrm{Six} \mathrm{cm}$ tracheal membrane laceration in an 83-year-old lady after emergency intubation. The mediastinal contents are covered with gastric aspirate and trachea-pleural communication causing pneumothorax with distinctive air leakage over the thoracic drain. Even a double lumen tube was unable to stop the air leak so endotracheal suture was successfully performed. Important to see is the retraction of the lateral tracheal membrane edges that complicates correct adaption during open posterior repair.

the rarity of TBIs especially in Germany where only 1,033 tracheobronchial injuries were documented over a 5 -years period with a predominance $(58 \%)$ of iatrogenic injuries followed by blunt trauma (26.7\%) and only 10 departments reported 5 or more TBIs per year (1) (Table 1).

\section{Management of iatrogenic posterior tracheal laceration}

Aetiology

Tracheal membrane laceration (TML) most often occur in the midline and the lower third of the trachea complicating endotracheal intubation, dilatational tracheostomy or rigid bronchoscopy in $0.05 \%$ to $0.5 \%(1,2)$. Risk factors for TML are well known: emergency intubation, late removal of guide rods during intubation, manipulation of the tube with a blocked cuff, uncontrolled dilatational tracheostomy, introduction beside the midline or pushing the bougie through cartilage rather than going through the intercartilage membrane. Furthermore, fragile tissue after long term use of corticoids, in obese patients and in postmenopausal short females are associated with TML $(2,3)$. The TML most often includes the posterior wall in the midline or right paramedian extending into the right main bronchus in some cases. In greater lesions the tube may completely dislocate into the posterior mediastinum leading to intermittent or persistent ventilation blockade and a rapid development of mediastinal emphysema and tension pneumothorax mainly on the right side (Figure 1).

\section{Symptoms}

Initial clinical signs are expanding mediastinal and subcutaneous emphysema, ventilatory resistance or high air leakage along the cuff and bloody secretions from the tube. If the patient was extubated, persistent coughing, shortness of breath and hemoptysis are highly suspicious of TML (4). 


\section{Diagnostics}

Confirmation of TML and classification of the injury, based on CT-scan evaluation, bronchoscopy and clinical signs are necessary and essential for further management. CTscan of the chest is well established for initial work-up when tracheal injury is suspected. TML may be detected by deep cervical air and pneumomediastinum, overdistention of the tube's balloon and tracheal wall defect or deformity (5). Chest X-ray is helpful when CT scan is unavailable, as it shows pneumothorax, mediastinal and subcutaneous emphysema and allows emergency drainage.

Three main categories have to be immediately evaluated:

(I) Establishing diagnosis: confirmation or exclusion of TML whenever this diagnosis is possible

(II) Categorize local injury: evaluation of the local situation including length and depth and location of the rupture, bleeding activity, protrusion of mediastinal structures and possible positioning of ventilation tube.

(III) Detect pneumothorax: collateral damages like pneumothorax or tension pneumothorax, injury to the esophagus, extension of mediastinum, subcutaneous and laryngeal emphysema, amount of air leakage along the tube or thoracic drains and others.

Concerning the local damage, Cardillo et al. (6) proposed a morphologic classification, based on the lacerated layers of the tracheal membrane. Level I and II injuries without complete disruption of the posterior tracheal membrane can be treated conservatively in most cases. Level IIIa TMLs are classified injuries with complete laceration of all tracheal layers and mediastinal soft tissue hernia into the lumen or broad communication of the airway with the mediastinum. Level IIIb is defined by additional esophageal injury or severe mediastinitis. As this "morphological" classification should "guide non-surgical treatment" (6), it is not helpful in every situation. Main aspects for treatment decisions are the length of the lesion, the amount of air leakage with pneumothorax, possibilities to bypass the lesion without expanding it with a blocked cuff and amount of mediastinal contents protrusion into the lumen. Furthermore, the current condition and prognosis of the patient is important for decision making.

\section{Initial management}

The initial management of the patient depend on its vigilance.
(I) Alert Conscious patients should have an urgent flexible bronchoscopy and chest $\mathrm{X}$-ray to rule out pneumothorax. If esophageal injury is suspected, the bronchoscope can be used for esophageal inspection simultaneously. lesions older than $24 \mathrm{~h}$ should be especially investigated with CT scan to estimate the amount of mediastinal inflammation and to plan operative repair when necessary.

(II) Intubated patients need an urgent flexible or rigid bronchoscopy and chest $\mathrm{X}$-ray to evaluate a possible pneumothorax. Orally intubated patients must be examined through the tube while pulling the tube slowly backwards to the upper end of the lesion or to the level of the vocal cords if a lesion must be ruled out. The tube can be gently positioned afterwards under visual guidance with the cuff distal to the lesion if possible. The cuff pressure should be as low as possible, a slight air leakage along the trachea may be tolerated (4). Patients with a tracheostomy cannot be evaluated through the tube because the rupture is most often opposite to the tube entry in the trachea. It is necessary to inspect the trachea from the larynx while slowly pulling the tracheostomy tube back until the tip is on the level of the tracheal front wall. We prefer rigid bronchoscopies in this situation because a secure airway is present even when the tracheostomy tube is accidentally pulled out. Using CT scan of the chest is very helpful in many situations to establish the diagnosis and recording associated problems including emphysema, mediastinitis and pneumothorax.

\section{Definitive management}

Definitive treatment of TML is conservative in case of level I and some level II lesions and open operative repair is imperative when esophageal injury is present as well (level IIIb injury) (6). The management of some of level II and full-thickness TML without esophageal injury (level IIIa laceration) are still a matter of debate $(2-4,6,7)$. In recent years there is a rise of publications supporting conservative treatment or stenting (8-10). There is a certain consensus that instable patients with a vague prognosis, requirement for long-term ventilation, short lesions and no difficulties to bridge the lesion are candidates for conservative treatment. Furthermore, the functional and medical risks of open repair have to be weighed against the achievement of 


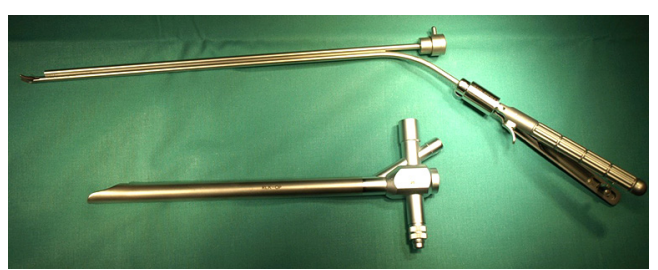

Figure 2 Rigid tracheoscope and optical needle holder (Karl Storz, Tuttlingen, Germany). Insertion of a fixed $4 \mathrm{~mm}$ and $12^{\circ}$ Hopkins telescope combination with a needle holder allows direct visualization of the needle and the surrounding anatomy and it may be connected with a video system. The tracheoscope can be connected with a jet ventilation system.

anatomic restoration of the trachea for every individual case. In case of long, full thickness TML with broad communication to the mediastinum, massive air leakage and relevant mediastinal herniation especially in obese patients' operative treatment is necessary. In all other level II and IIIa lesions individual decisions depend on local availability of treatment options and experience (4). Severe mediastinal and subcutaneous emphysema may be relieved by $1 \mathrm{~cm}$ subclavicular skin incisions that remain open, just covered with sterile gauze. A contemporary algorithmic approach for treatment of iatrogenic tracheobronchial injuries was delivered in 2019. Unfortunately, they did not include the possibility of endotracheal repair (11).

\section{Conservative treatment}

* Rest: alert patients with small lesions can be observed with antitussive medication and rest. Persistent cough repeatedly opens the tracheal tear and disturbs local healing and needs to be suppressed. Broad spectrum antibiotics are recommended although evidence is small (3).

* Bypass with ventilation tube is useful in patients who need long term ventilation and have uncertain prognosis. The cuff must be placed distally in healthy tissue. If not possible, double lumen tube intubation for 3-4 days is reasonable. After several days, smaller lesions will be covered by a layer of fibrin that occludes the TML.

* Fibrin glue may be used to cover level II and IIIa lacerations. Cardillo et al. (6) reported successful treatment with endoscopic instillation of fibrin glue. He reported about 3 patients with Level I, 24 patients with level II and 2 patients with level IIIA TML. Figure 4 in his publication shows a level II laceration healed with a large gap of the membrane, but covered with epithelium.
* Stent implantation was used to bridge TML in an 86 years old lady. To manage retention of bronchial secretions the patient needed tracheostomy. After 14 days the stent was removed via rigid bronchoscopy and the posterior trachea documented with a large gap of the membrane but covered with scar tissue and epithelium. The lady had initial cardiac arrest and was categorized not able to tolerate thoracotomy (12). A further case received Dumont stent introduction during right sided VATS and TML without delay. The patient was extubated next day and discharged on day 4. Stent removal was performed after 13 months. Complete healing of the tracheal membrane was stated (13). In another case nitinol stent implantation was performed at day 5 after TML from emergency intubation and ventilation. The 63 years old lady exhibited tracheal obstruction immediately after extubation due to mediastinal herniation into a $5-\mathrm{cm}$ TML. The stent remained 3 months. Despite some granulation tissue at the ends of the stent, there were clinically no signs of airway collapse found after removal (14).

* Tracheostomy is described being a simple alternative to open surgical repair as it reduces intratracheal pressure and air leakage through the tear, thereby allowing spontaneous healing of the rupture (8). The authors bypassed the lesion with a tracheostomy tube and performed operative closure 1-2 months later successfully in 3 patients. They indicate that direct intraluminal suture of proximal tracheal lacerations can be performed through the tracheal stoma in a minimally invasive manner.

\section{Operative repair}

* Open TML repair is usually performed via right posterolateral thoracotomy through the fourth intercostal space. The mediastinal pleura is opened to expose the lesion. Because the wound edges are usually retracted to the chondral angles, it is very important to begin suturing in healthy membrane tissue and expose the stable membrane edges for every single stich. Continuous running suture or interrupted sutures with resorbable threads are used (Video 1). If mediastinitis or inflammatory changes prevent the adaptation of the membrane edges, pedicled muscle flaps (pectoralis major) may be used to cover the suture line and to prevent the formation of an esophagotracheal fistula (7).

* Video assisted TML repair was described through a 
cervical incision and opening of the trachea. A 0-degree, 5-mm camera and an endoscopic needle holder were introduced through the tracheal incision and a running suture with a polyglactin 4-0 suture beginning at the proximal end which was performed in combination with intermittent ventilation. The sutures looked good after 14 days and patients could be discharged (15). Their experience includes two cases.

* Endoluminal repair was described 2011 (16). In our own experience we prefer complete endotracheal repair for every patient with level II and IIIa lacerations longer than $3 \mathrm{~cm}$ who can tolerate jet ventilation. Endotracheal repair with a 70-cm 2-0 Vicryl thread (UCLX-needle, Ethicon, Germany) is performed using a shortened $14 \mathrm{~mm}$ rigid tracheoscope and an optical needle holder (KARL STORZ Endoscopes, Germany) (Figure 2) (16). We gained experience with 18 cases since 2008. Anatomic restoration of the trachea was achieved in 17 cases with no local complications. The procedure is technically demanding, but is well tolerated. Stable patients can be extubated at the end of the procedure, patients with a need for longer ventilation may be regularly intubated or can have tracheostomy without the risk of tube dislocation into the mediastinum (Video 2). No procedure associated complications were registered.

\section{Outcome}

Because the wound edges retract and positive pressure opens the TML there is no spontaneous stable healing of larger tears at all. A layer of fibrin arises first and a thin layer of epithelial cells grow later on the mediastinal contents protruding into the lumen while the patient coughs. This is exactly comparable to an incisional hernia and can be detected during flexible bronchoscopy months after conservative treatment. Exact analysis of photographs from published cases after conservative treatment demonstrate the persistence of a circumscribed weak area where mediastinal contents are epithelialized but no adaption of the ruptured edges have occurred $(6,8,9)$. When the patient coughs, complete occlusion of the tracheal lumen can be seen. This phenomenon will always be overseen in rigid bronchoscopy or in deep sedation or intubated patients (4). Tracheal stents may induce more scar tissue and may be associated with more stable posterior tracheal wall after treatment (14), but they have their well-known problems like retention of secretions, granulation tissue formation at the stent ends and stent migration in some patients.
Further reports are warranted. Sequelae of posterolateral thoracotomies are well-known from lung cancer surgery and includes chronic pain, impairment of shoulder movement and numbness of the chest wall. In critically ill patients, additional thoracotomy my increase mortality rate. On the other hand, there are no reports about systematic followup of patients after conservative or operative TML repair so that advantages or disadvantages are completely unclear concerning mid- and long-term outcome.

It is the authors view that TML, being an iatrogenic injury to the patient, should be repaired whenever possible with a method causing no or only minimal collateral damage. Therefore, transtracheal minimally invasive repair or completely intraluminal repair should be offered whenever the patient tolerates interrupted ventilation or jet ventilation.

\section{Management of intra- and perioperative tracheobronchial complications}

The number of intraoperative tracheobronchial injuries are unknown. It may occur during lung resection, esophagectomy, mesothelioma or empyema surgery and especially during radical lymph node dissection. Especially esophagectomy and gastric pull-up bears the risk for trachea-bronchial fistula development at the site of injury or tissue ischaemia (17). The diagnosis is established by intraoperative direct visualization or during saline submersion test. TML from intubation may be identified during right sided operative procedures as well.

(I) Repair: accidental cuts can be repaired by direct suturing. When a tracheal tear is detected intraoperatively during cardiothoracic surgery, even when it is caused by intubation, it is best to treat it surgically (11). Narrowing or transection of tracheobronchial structures can be repaired by creation of anastomoses or slide bronchoplasties to enlarge the lumen. Techniques are described in common thoracic surgery text books $(18,19)$.

(II) When local tissue ischaemia arises following radical resection, lymph adenectomy or debridement, then covering with viable muscle flaps or omentum is recommended (4). Preferred muscle flaps are pectoralis major, intercostal and sometimes latissimus muscle. Direct suturing of tracheobronchial injury and covering with a muscle flap even in the situation of postoperative complicating fistula and infection or when gastro-tracheal fistula developed proved to lead to fistula resolution in 6 of 6 patients (20). 
Table 2 Mode of repair for intraoperative tracheobronchial injuries

\begin{tabular}{ll}
\hline Mode of injury & Mode of repair \\
\hline Local cut, local incision & Primary suture or bronchoplasty with end-to-end anastomosis \\
$\begin{array}{ll}\text { Local excision or thermal damage with } \\
\text { tissue ischaemia }\end{array}$ & $\begin{array}{l}\text { Local debridement and coverage with vital muscle flap (intercostal, diaphragmatic, pectoralis } \\
\text { major or latissimus) or omentum flap }\end{array}$ \\
\hline
\end{tabular}

Others reported a $3.5 \%$ rate of intraoperative sustained injury to the tracheobronchial tree during oesophagectomy. All injuries were repaired primarily and reinforced with an intercostal muscle flap. One patient with an injury of the cervical part of the trachea repair was done primarily and reinforced with cyanoacrylate glue. At follow-up no evidence of repair breakdown was found (17) (Table 2).

\section{Management of blunt trauma and penetrating injury}

Many review articles are written about tracheobronchial blunt or penetrating trauma $(4,11,21-24)$. These injuries are rare $(2-3 \%$ of trauma patients) and often $(30-80 \%)$ fatal before arriving hospital due to asphyxia, tension pneumothorax or concomitant injury to the heart and great vessels $(1,4,11,23)$. The mortality of patients with tracheobronchial injuries (TBI) arriving to hospital can be as low as $9 \%$. On the other side $40-100 \%$ of victims with TBI have life threatening co-existing injuries which are responsible for the outcome (hemopneumothorax $32 \%$, esophageal injuries (11\%), major vascular injuries (18\%), cardiac injuries (5\%), spinal cord injuries $(7 \%)$, intraabdominal injuries (18\%), as well as left recurrent nerve, ascending and descending aorta and pulmonary arteries $(22,23,25)$. Most TBI after blunt trauma $(76 \%)$ involve the main bronchi within $1 \mathrm{~cm}$ from the carina (22). Shotgun injuries always leave a certain amount of disrupted and thermal damaged tissue around the bullet canal. If parts of the airway are damaged by a bullet, local debridement is important before reconstruction as otherwise attached necrotic tissue will not heal (4).

Due to the lack of larger series or studies only some general statements can be made concerning medical management. The management of those patients include to establish and maintain a secure patent airway and to repair the injury with no impairment of respiratory function if possible. The management should be accompanied by a multidisciplinary team to immediately treat co-injuries if needed. The inclusion of the thoracic surgeon is necessary in any penetrating thoracic injury; when the blood loss through the chest drain is $>1,500 \mathrm{~mL}$ initially or $>200 \mathrm{~mL} /$ hour over 2-4 hours; when haemoptysis is present, when massive subcutaneous emphysema occurs or substantial air-leakage over the chest tube; when chest X-ray or CT thorax shows uncertainty of possible thoracic injuries (26). If mechanical ventilatory support fails adequate oxygenation because of the underlying injury, extracorporeal membrane oxygenation or cardio-pulmonary bypass may be required as a bridge to recovery or to allow definitive surgical intervention $(21,23,27)$. The principles of airway repair are simple: frugal local debridement of the most damaged tissue and individual sutures of the tracheobronchial wall, if necessary, complex reconstruction techniques may be needed $(18,21,26)$.

\section{Approach}

Due to current resuscitation guidelines, the ABCDE approach (Airway, Breathing, Circulation, Disability, Exposure) is used to assess and treat the trauma patient (28). As long as a stable airway can be established and ventilation is adequate, the treatment of TBI can be postponed until other life-threatening injuries are repaired and the patient is stabilized (24). If a ruptured airway or a disrupted bronchus prevents adequate oxygenation or ventilation, immediate repair is necessary. The ideal management depends on every individual case and circumstance. When cervical injury is present, the wound needs exploration and may be used to insert ventilation tube. Insertion of two or more thoracic drains are sometimes necessary to prevent tension pneumothorax in ventilated TBI patients but they can lead to massive air leakage and inadequate oxygenation as well. In this situation emergency sternotomy/thoracotomy or bronchoscopic evaluation when available, are the next step to correct diagnosis and decision making (Table 3).

\section{Operative strategies}

Modern techniques of repair have eliminated many of the 
Table 3 Management strategy for penetrating trachea-bronchial injuries

\begin{tabular}{ll}
\hline Treatment categories & Management of penetrating injury \\
\hline First step & $\begin{array}{l}\text { Establish secure air way with single lumen tube, tracheostomy/coniotomy in case of laryngeal damage or } \\
\text { double lumen tube placed under bronchoscopic control }\end{array}$ \\
Control co-injuries & Drain pneumothorax, evaluate vascular, cerebral and abdominal injuries and categorize their severity \\
Treatment & Plan stepwise treatment of the injuries within a multidisciplinary team \\
Immediate thoracic & $\begin{array}{l}\text { Blood loss } \geq 1,500 ~ \\
\text { of mechanical ventilation; severe tracheobronchial air-leakage or bleeding; injury of the heart or large vessels } \\
\text { operative intervention } \\
\text { (blood loss/pericardial tamponade) }\end{array}$ \\
Airway repair & $\begin{array}{l}\text { Operative trachea-bronchial repair can be performed in stable patients or immediately when a secure airway } \\
\text { cannot be established due to massive air leakage, bleeding or obstruction }\end{array}$ \\
\hline
\end{tabular}

complications noted in the past. Basic principles include to preserve healthy tissue, and keep peritracheal dissection minimal, use absorbable sutures and omit protective tracheostomies. In a series with 22 injured cases with stab wounds or gun shots combined injuries of cervical trachea and oesophagus or carotid artery was found in 12. Repair consisted of direct tracheal suture and coverage with vascularized flaps between trachea and esophagus in 10 . Nonetheless seven significant complications occurred with one death (29). Operative freshening of the injured bronchial edges and anastomosis is indicated when the lung tissue is viable and re-expansion can be achieved (19). Otherwise if the lung tissue is destroyed and re-expansion cannot be achieved, sleeve resection and anatomic lung resection is necessary $(4,21,22,24,30)$.

\section{Outcome}

TBI will be missed in $25-80 \%$ at primary evaluation and organized hematoma and granulation tissue formation will arise. Therefore, patients presenting with bronchiectasis, lung atelectasis and infection with a history of major chest trauma should have bronchoscopy and may have delayed diagnosis of TBI $(23,30)$. Conservative treatment or no treatment of blunt TBI had the highest mortality whereas operative repair had less mortality than resection (22). Interestingly patients who had their diagnosis within $24 \mathrm{~h}$ had a mortality of $25 \%$ compared with $3 \%$ mortality when diagnosis was detected more than 7 days after the injury. This context may reflect the fact that early detection of blunt tracheobronchial trauma is associated with more concomitant injuries and thus higher mortality $(22,23)$. If a patent airway can be established early, the outcome of TBI patients mainly depend on the severity of other injuries like serial rib fractures, flail chest, lung contusion, injuries of the liver and spleen, injuries of great vessels and the heart and cranial trauma. Operative restoration of the bronchial system most often heals without sequelae (24).

\section{Conclusions}

Tracheo-bronchial injuries are often life threatening and require early and skillful airway management, experienced evaluation, and qualified operative repair in thoracic surgery units. The management of TBIs differ widely by its underlying causation. While establishing a stable airway and treatment of concomitant injuries is the main priority in trauma patients, bronchoscopic evaluation and bridging of the tracheal membrane laceration with the tube in situ is the first measure after iatrogenic TML. The prognosis of trauma patients is dominated by life threatening injuries of other organs whereas comorbidity dominates outcome in TML patients. Operative repair is the state of the art in traumatic TBI and conservative, interventional or operative treatment must be discussed in every individual case of TML.

\section{Acknowledgments}

Funding: None.

\section{Footnote}

Provenance and Peer Review: This article was commissioned by the Guest Editor (Servet Bölükbas) for the series " Airway Surgery" published in fournal of Thoracic Disease. The article was sent for external peer review organized by the Guest Editor and the editorial office. 
Conflicts of Interest: Both authors have completed the ICMJE uniform disclosure form (available at http://dx.doi. org/10.21037/jtd-2019-as-05). The series "Airway Surgery" was commissioned by the editorial office without any funding or sponsorship. SW serves as the unpaid editorial board member of Fournal of Thoracic Disease from May 2019 to Apr 2021. The other author has no other conflicts of interest to declare.

Ethical Statement: The authors are accountable for all aspects of the work in ensuring that questions related to the accuracy or integrity of any part of the work are appropriately investigated and resolved.

Open Access Statement: This is an Open Access article distributed in accordance with the Creative Commons Attribution-NonCommercial-NoDerivs 4.0 International License (CC BY-NC-ND 4.0), which permits the noncommercial replication and distribution of the article with the strict proviso that no changes or edits are made and the original work is properly cited (including links to both the formal publication through the relevant DOI and the license). See: https://creativecommons.org/licenses/by-nc-nd/4.0/.

\section{References}

1. Schneider T, Volz K, Dienemann H, et al. Incidence and treatment modalities of tracheobronchial injuries in Germany. Interact Cardiovasc Thorac Surg 2009;8:571-6.

2. Miñambres E, Burón J, Ballesteros MA, et al. Tracheal rupture after endotracheal intubation: a literature systematic review. Eur J Cardiothorac Surg 2009;35:1056-62.

3. Conti M, Pougeoise M, Wurtz A, et al. Management of postintubation tracheal membrane rupture. Chest 2006;130:412-8.

4. Welter S. Repair of tracheobronchial injuries. Thorac Surg Clin 2014;24:41-50.

5. Chen JD, Shanmuganathan K, Mirvis SE, et al. Using CT to diagnose tracheal rupture. AJR Am J Roentgenol 2001;176:1273-80.

6. Cardillo G, Carbone L, Carleo F, et al. Tracheal lacerations after endotracheal intubation: a proposed morphological classification to guide non-surgical treatment. Eur J Cardiothorac Surg 2010;37:581-7.

7. Gabor S, Renner H, Pinter H, et al. Indications for surgery in tracheobronchial ruptures. Eur J Cardiothorac Surg 2001;20:399-404.

8. Ovári A, Just T, Dommerich $\mathrm{S}$, et al. Conservative management of post-intubation tracheal tears-report of three cases. J Thorac Dis 2014;6:E85-91.

9. Tazi-Mezalek R, Musani AI, Laroumagne S, et al. Airway stenting in the management of iatrogenic tracheal injuries: 10-Year experience. Respirology 2016;21:1452-8.

10. Geltner C, Likar R, Hausegger K, et al. Management of Postintubational Tracheal Injury by Endoscopic Stent Placement: Case Report and Review of the Literature. Thorac Cardiovasc Surg Rep 2016;5:8-12.

11. Grewal HS, Dangayach NS, Ahmad U, et al. Treatment of Tracheobronchial Injuries: A Contemporary Review. Chest 2019;155:595-604.

12. Yamamoto S, Endo S, Endo T, et al. Successful silicon stent for life-threatening tracheal wall laceration. Ann Thorac Cardiovasc Surg 2013;19:49-51.

13. Marchese R, Mercadante S, Paglino G, et al. Tracheal stent to repair tracheal laceration after a double-lumen intubation. Ann Thorac Surg 2012;94:1001-3

14. Lee BE, Korst RJ. Successful Treatment of an Iatrogenic Tracheal Laceration With a Temporary PolyurethaneCoated Nitinol Stent. Ann Thorac Surg 2016;102:e11-2.

15. da Silva Costa A Jr, Juliano Perfeito JA, Succi JE, et al. A video-assisted endotracheal suture technique for correction of distal tracheal laceration after intubation. Ann Thorac Surg 2012;93:2073-5.

16. Welter S, Krbek T, Halder R, et al. A new technique for complete intraluminal repair of iatrogenic posterior tracheal lacerations. Interact Cardiovasc Thorac Surg 2011;12:6-9.

17. George SV, Samarasam I, Mathew G, et al. Tracheal injury during oesophagectomy--incidence, treatment and outcome. Trop Gastroenterol 2011;32:309-13.

18. Grillo HC. Repair of tracheobronchial trauma. In: Grillo HC. Surgery of the trachea and bronchi. London: BC Decker Inc. Hamilton 2002; 631-44.

19. Bölükbas S, Schirren J. Parenchyma-sparing bronchial sleeve resections in trauma, benign and malign diseases. Thorac Cardiovasc Surg 2010;58:32-7.

20. Morita M, Saeki H, Okamoto T, et al. Tracheobronchial fistula during the perioperative period of esophagectomy for esophageal cancer. World J Surg 2015;39:1119-26.

21. Symbas PN, Justicz AG, Ricketts RR. Rupture of the airways from blunt trauma: treatment of complex injuries. Ann Thorac Surg 1992;54:177-83.

22. Kiser AC, O'Brien SM, Detterbeck FC. Blunt tracheobronchial injuries: treatment and outcomes. Ann Thorac Surg 2001;71:2059-65.

23. Prokakis C, Koletsis EN, Dedeilias P, et al. Airway trauma: 
a review on epidemiology,mechanisms of injury, diagnosis and treatment. J Cardiothorac Surg 2014;9:117.

24. van Roozendaal LM, van Gool MH, Sprooten RTM, et al. Surgical treatment of bronchial rupture in blunt chest trauma: a review of literature. J Thorac Dis 2018;10:5576-83.

25. Kelly JP, Webb WR, Moulder PV, et al. Management of airway trauma. I: Tracheobronchial injuries. Ann Thorac Surg 1985;40:551-5.

26. Ludwig C, Koryllos A. Management of chest trauma. J Thorac Dis 2017;9:S172-7.

27. Antonacci F, De Tisi C, Donadoni I, et al. Veno-venous

Cite this article as: Welter S, Essaleh W. Management of tracheobronchial injuries. J Thorac Dis 2020;12(10):6143-6151. doi: $10.21037 /$ jtd-2019-as-05
ECMO during surgical repair of tracheal perforation: A case report. Int J Surg Case Rep 2018;42:64-6.

28. Soar J, Nolan JP, Böttiger BW, et al. Adult advanced life support section Collaborators. European Resuscitation Council Guidelines for Resuscitation 2015: Section 3. Adult advanced life support. Resuscitation 2015;95:100-47.

29. Lyons JD, Feliciano DV, Wyrzykowski AD, et al. Modern management of penetrating tracheal injuries. Am Surg 2013;79:188-93.

30. Glazer ES, Meyerson SL. Delayed presentation and treatment of tracheobronchial injuries due to blunt trauma. J Surg Educ 2008;65:302-8. 